tion (BIO, Washington, DC) and CEO of Genzyme Corp. (Cambridge, MA). "We're grateful David Kessler gave us a chance and reached out to make things better. This will cut useless paperwork and save substantial time and money." But biotechnology is not on terms yet. "BIO will continue to pursue FDA through Congress," said the organization's president, Carl Feldbaum.

Among her new proposed legislative reforms, Senator Kassenbaum is seeking to mandate the use of contract reviewers if agency officials fail to meet stringent "performance standards" that are to include strict deadlines for the agency to meet when evaluating candidate therapeutics and medical devices. The likelihood that this bill will move through Congress is difficult to measure, however. Congress and the Administration are locked in a marathon budget battle that continues to distract attention from most other issues.

Nonetheless, agency reforms continue to take shape. In midDecember, for example, FDA officials met with industry representatives as part of an ongoing effort to refine the agency's definition of "well-characterized therapeutic recombinant DNA-derived and monoclonal antibody biotechnology products."

There now seems to be little obvious difference between the definitions of "well-characterized products" from industry representatives on the one hand and agency officials on the other. Both identify remarkably similar criteria, such as known amino acid sequences and relevant higher-order structure, as well as posttranslational modifications, quantifiable purity, and availability of appropriate measures of biological activity. It is still an open question whether FDA will extend this definition to include some of the newer rDNAderived and subunit vaccines.

Agency officials expect to publish an amended version of the definition before the end of February. Industry representatives say that, although there is good general agreement, the important remaining questions have to do with how FDA will finalize and then implement these new policies and definitions.

一Jeffrey L. Fox

\section{Biopatents in Europe reopened}

OXFORD, U.K.-European legislators will have another go at producing specific legislation to protect biotechnological inventions. Less than a year after the European Parliament (EP, Strasbourg, France) rejected a joint textapproved by theConciliation Committee - which consisted of representatives of the European Commission (Brussels, Belgium) and EP-new proposal foranEPandEuropeanCouncil directive has been proposed by the European Commission.

The move is believed to be in response to pressure from Europe's Intemal Market Commissioner Mario Monti. "Without common legislation compatible with the single market," Monti explained, "European research and exploitation of its results, particularly for therapeutic purposes, will be discouraged and placed at a disadvantage compared with competitors in [non EU] countries." The commission consulted widely with "all interested parties," and is convinced that its new proposal achieves the right balance between what it believes are "the two equally essential requirements" of promoting research and providing ethical protection. When the earlier proposals fell in 1995, industry representatives seemed apathetic at the prospect of a further struggle through the legislative quagmire.

The new proposal, which is said to take full account of the EP's ethical concerns and its call for clarity, states clearly that a discovery cannot be patentable, and stipulates the conditions subject to which an invention may be patented. It completely excludes from patentabilitymethods of germ-line(but not somatic cell) gene therapy on humans. In highly convoluted language ("a part isolated from the human body. . may not be regarded as not being patentable..."), the new directive does appear to allow patenting of body parts "not in their natural state." It would also introduce directly into law an exceptionforlivestockfarmersthatwould allow them touse part of their breeding stock to replenish stock numbers.
The new

proposal is

said to take

full account

of the EP's

ethical

its call for

clarity. concerns and

\section{THE FOURTH INTERNATIONAL} genetics CONFERENCE

In Association with the Canadian Genetics Diseases Network GENETIC SUSCEPTIBILITY \& COMPLEX TRAITS

The Westin Bayshore - Vancouver, Canada • April 17-19, 1996

Genetic Susceptibility \& Complex Traits, the Fourth Annual North American conference hosted by Nature Genetics, will explore these issues in depth, including the strategies required to analyze complex traits and the latest successes in isolating genes for common genetic diseases. In addition, the meeting will also focus on the interaction of genes and environmental factors in specific disorders, and the latest revelations in the genetic diversity of, and susceptibility to, infectious organisms. The final session will reveal what is presently known about the genetic basis of behavior, including memory and sexual predisposition. There will be at least one talk devoted to "late-breaking research," for which those interested are invited to contact the Editor.

Among the speakers will be:

Aravinda Chakravarti (Case Western Reserve, Cleveland)

Jeffery Friedman (Rockefeller University, New York)

Dean Hamer (National Institutes of Health, Bethesda)

Michael Hayden (University of British Columbia, Vancouver)

Adrian Hill (John Radcliff Hospital, Oxford)

Peter St George Hyslop (University of Toronto, Toronto)

Mary-Claire King (University of Washington, Seattle)

Jacques Mallet (C.N.R.S., Paris)

Nick Martin (Queensland Inst. of Medical Research, Brisbane)

Joseph Nadeau (McGill University, Montreal)

Leena Peltonen (National Public Health Institute, Helsinki)

Stanley Prusiner (University of California, San Francisco)

Michael Rose (University of California, Irvine)

Emil Skamene (McGill University, Montreal)

Glenys Thomson (University of California, Berkeley)

Susumu Tonegawa (M.I.T., Cambridge)

Doug Wallace (Emory University, Atlanta)

Wednesday April 17, 1996 Gala Dinner (Guest Speaker to be announced)

For more information or to register please contact the Conference Department.

Phone: (212) 726-9281 Fax: (212) 696-9594 e-mail: conference@natureny.com 